\title{
Interações criança-criança e a coconstrução da linguagem: uma análise qualitativa
}

\author{
Child-child interactions and the co-construction of \\ language: a qualitative analysis
}

\begin{abstract}
Viviane Fernandes Faria Pinto ${ }^{[a]}$, Diva Maria Moraes Albuquerque Maciel ${ }^{[b]}$
[a] Mestre em Processos de Desenvolvimento Humano e Saúde (UnB) e Especialista em Desenvolvimento Psicológico e Inclusão Escolar, atuou como técnica do MEC em programas de formação de professores e como orientadora educacional pela Secretaria de Educação do Distrito Federal, vinculada ao Instituto de Estudos e Pesquisas Educacionais Anísio Teixeira (Inep), Brasília, DF, Brasil, e-mail: viviane.educ@gmail.com

[b] Doutora em Educação pela Universidade de São Paulo (USP), Realizou estudos Pós-Doutorais na Clark University, USA, Pesquisadora Associada do Departamento de Psicologia Escolar da UnB, orientando trabalhos de mestrado e doutorado, Brasília, DF, Brasil, e-mail: diva@unb.br
\end{abstract}

\section{Resumo}

Este artigo objetiva discutir as contribuições das interações entre pares para o processo de aprendizagem de crianças com necessidades especiais. Baseia-se em um estudo qualitativo orientado pela teoria sociocultural-construtivista, que analisou as estratégias comunicativas utilizadas por crianças em episódios de interação registrados em vídeo. Participaram do estudo crianças com idades variando entre 4 e 5 anos, entre elas duas 
irmãs gêmeas que apresentavam atrasos no desenvolvimento da oralidade. $O$ estudo indica que os contextos interativos são fundamentais para a aprendizagem: verificou-se que as interações das crianças com distúrbios de linguagem exigem a utilização de diferentes estratégias comunicativas, o que resulta em possibilidades diversas de desenvolvimento. Conclui-se, no entanto, que os contextos inclusivos, embora permitam diferentes possibilidades de desenvolvimento, necessitam da mediação pedagógica com vistas à superação de possíveis obstáculos.

Palavras-chave: Interações. Desenvolvimento. Aprendizagem. Inclusão escolar.

\section{Abstract}

This paper discusses the contributions of interactions between peers in the learning process of children with special needs. It is based on a qualitative study guided by socio-constructivist theory, which examined the communication strategies used in interactive episodes, recorded on video. The study participants were five children aged between 4 and 5 years, and two of these children are twin sisters who had developmental delays of oral language. The study indicates that the interactive contexts are critical for learning: it was found that the interactions of children with language disorders require the use of different communication strategies, which results in several possibilities for development. We conclude, however, that although inclusive space offers different possibilities for development, it needs pedagogical mediation aiming to overcome possible obstacles.

Keywords: Interactions. Development. Learning. School inclusion.

\section{Introdução}

Apesar de o discurso acerca do ideal de aceitação e valorização das diferenças estar cada vez mais disseminado, verifica-se que as escolas ainda enfrentam dificuldades para implementar modelos inclusivos e efetivar práticas que cumpram as proposições de uma educação com qualidade para todos. Apesar dessas dificuldades, não se pode desconsiderar o 
valor intrínseco das práticas inclusivas dadas às múltiplas possibilidades de desenvolvimento e aprendizagem propiciadas pelas interações promovidas nesse espaço. Por outro lado, a literatura indica a necessidade de que mais estudos empíricos sejam realizados, a fim de desvelar o processo de inclusão, contribuindo, assim, para a melhoria dessas práticas de ensino.

Com o objetivo de contribuir para a discussão de aspectos relativos às interações entre pares para o processo de desenvolvimento de crianças com necessidades especiais, o presente artigo apresenta um recorte de um estudo mais amplo, desenvolvido com base em uma metodologia qualitativa que se propôs analisar as estratégias comunicativas verbais e não verbais utilizadas durante episódios interativos criança-criança, com foco nas possibilidades de promoção do desenvolvimento e aprendizagem de crianças com necessidades especiais.

\section{Desenvolvimento, interação e linguagem na perspectiva sociocultural-construtivista}

Ao se abordar o desenvolvimento humano, não é possível considerar a influência de um único aspecto ou de uma única perspectiva. Ao contrário, concebe-se o desenvolvimento humano como resultado de uma multiplicidade de influências, fatores e causas que estão imbricados e interrelacionados. O desenvolvimento humano, portanto, não acontece de forma linear, mas resulta de um complexo sistema de interações travadas pelo sujeito durante seu processo de maturação, que não se restringe aos aspectos biológicos. É necessário considerar, por exemplo, as diversas interações estabelecidas entre pares em seus múltiplos ambientes, com o próprio ambiente e com as mensagens presentes no universo histórico e cultural com os quais o sujeito dialoga ao longo da vida, entre outros. Isso significa que o processo de construção do conhecimento acontece a partir da interação e inter-relação de fatores internos e externos ao indivíduo e que essa construção tem como uma das características principais a multiplicidade de fatores imbricados nesse complexo processo (VALSINER, 2007). Essa 
característica interativa, dialógica e coconstrutiva inerente ao desenvolvimento humano aponta para a importância das interações estabelecidas tanto para a aprendizagem quanto para a própria constituição subjetiva do sujeito. Nessa perspectiva, enfatiza-se tanto a postura ativa do sujeito em seu processo de desenvolvimento como a importância do contexto sociocultural do qual ele participa (MACIEL; BRANCO; VALSINER, 2004).

A relação entre desenvolvimento e aprendizagem se dá entremeada pelas interações e relações sociais estabelecidas e, por isso, tal relação é sempre mediada pelos símbolos e significados culturais socialmente compartilhados. Uma importante abordagem, ao se tratar do desenvolvimento humano, é a teoria sociocultural-construtivista que surge a partir da síntese criadora entre os postulados da teoria de Piaget e as proposições e estudos de Vygotsky (BRANCO; ROCHA, 1998; MADUREIRA; BRANCO, 2005; VALSINER, 1989, 2007). Essa perspectiva evidencia a gênese social da aprendizagem e do desenvolvimento em que tais processos são percebidos como resultado de multi-influências e fatores interconectados, impregnados de significados culturais. O modelo bidirecional, que pressupõe uma relação dialógica e de mútua constituição entre sujeito e cultura, também é um fator importante quando pensamos no desenvolvimento humano (VALSINER, 1989, 1998, 2007).

De acordo com a perspectiva sociocultural-construtivista, a cultura exerce um papel primordial no processo de construção do desenvolvimento. Esse aspecto singular da espécie, ao mesmo tempo em que é produzido e modificado pelos seres humanos, também os modifica, transforma e regula suas ações. Assim, esse processo se constitui dialeticamente em uma via de mão dupla, o que ressalta a natureza social da personalidade humana, que se processa no movimento de internalização e externalização de fenômenos psicológicos (VALSINER, 1998, 2007). A construção de significados resulta, pois, de um processo dialógico dinâmico que ocorre em contextos que são culturalmente estruturados. Nesse sentido, podemos afirmar que todas as mensagens culturais que os indivíduos recebem ao longo do desenvolvimento são reelaboradas e ressignificadas ativamente e externalizadas de alguma maneira. 
O papel da cultura na constituição humana deve ser considerado a partir de um processo de mútua constituição entre a pessoa e o mundo social. De acordo com Valsiner (1998, 2007), o papel da cultura deve ser percebido a partir de uma relação processual bidirecional e não como um aspecto puramente regulador das ações humanas. Nesse movimento, a própria constituição do sujeito será resultado de um processo coconstrutivo, inter-relacional e dialógico repleto de influências históricas e culturais que, apesar de atuar de forma preponderante na constituição humana, não podem ser encaradas de forma determinista (VALSINER, 1998). Assim, esse processo bidirecional elabora-se em termos de apropriação ou de participação orientada do indivíduo nos eventos e práticas sociais, o que pressupõe ação ativa do sujeito neste processo de mútua constituição entre indivíduo-sociedade. Esse processo dialético e bidirecional de constituição humana é reafirmado por Geertz (1996). Sob o ponto de vista desse antropólogo, o ser humano não é apenas produtor da cultura, mas também, em um sentido biológico, é produto dessa mesma cultura. Partindo de uma perspectiva similar, Rogoff (2006) contribui com esse entendimento ao apresentar pesquisas que apontam para a intersecção entre os processos de desenvolvimento biológico e a cultura, conforme indicativos de estudos a respeito de diferenças verificadas no desenvolvimento de bebês em distintas comunidades culturais.

Para a perspectiva sociocultural-construtivista, durante as trocas dialógicas reconstruímos as informações continuamente. A cultura é, assim, transformada em tempo real pelos participantes do discurso social. Por essa perspectiva, enfatiza-se tanto a postura ativa do sujeito em seu processo de desenvolvimento quanto à importância do contexto sociocultural no qual ele se insere (MADUREIRA; BRANCO, 2005). O desenvolvimento humano, portanto, processa-se na intrínseca relação dialética entre processos biológicos e culturais, bem como em processos externos e internos aos indivíduos, nos quais a canalização cultural e a ação ativa do sujeito atuam na promoção do seu próprio desenvolvimento (VALSINER, 2007).

Com base nessas discussões, é possível (re)afirmar, a partir da perspectiva sociocultural-construtivista, a importância e a centralidade da 
interação social e do contexto cultural para o desenvolvimento. Essa perspectiva, portanto, aponta para uma superação de entendimentos reducionistas em relação ao desenvolvimento humano, compreendido de forma mais ampla e multidisciplinar. Assim, as múltiplas possibilidades de constituição social do desenvolvimento, aprendizagem e cultura ocorrem entremeadas pelas diferentes vozes, experiências, emoções e valores vivenciados, compartilhados e coconstruídos, durante o curso de desenvolvimento. Isso significa que o ser humano é constituído pela interdependência da ação do próprio sujeito com os significados que se constroem sobre ele a partir do diálogo estabelecido com os "outros sociais". Pode-se afirmar, portanto, que o processo de significação ou constituição do desenvolvimento perpassa pelo diálogo e pelo significado entre o "eu" e os "outros" que se inicia com a vida humana (ROSSETI-FERREIRA; AMORIM; SILVA, 2004).

Nesse sentido, os processos de socialização vivenciados são aspectos importantes de apoio para o desenvolvimento e aprendizagem humanos. Diversos teóricos e estudos têm destacado a importância das interações e do contexto cultural para a coconstrução do conhecimento e aprendizagem da criança. Esses estudos mostram que a qualidade das interações estabelecidas no cotidiano e nos diferentes contextos é algo fundamental para impulsionar o desenvolvimento humano de forma global e saudável (ANJOS et al., 2004; BRANCO, 2006; BORGES; SALOMÃO, 2003; MACIEL; BRANCO; VALSINER, 2004). Essa questão é sintetizada por Vygotsky (1994) quando ele afirma que o homem é um ser social que, sem as interações, nunca poderá desenvolver nenhum de seus atributos e características.

A partir do entendimento do desenvolvimento humano constituído de forma dinâmica e dialógica, compreende-se a importância dos processos comunicativos verbais e não verbais para o desenvolvimento e, consequentemente, para a constituição subjetiva do sujeito. Compreende-se o desenvolvimento enquanto processo passível de mudança a depender dos diferentes contextos, períodos temporais, experiências, valores e emoções coconstruídas em determinados grupos sociais. A partir dessas considerações, compreende-se o desenvolvimento humano impulsionado e constituído pelas práticas sociais dadas em um contexto cultural. Práticas culturais 
essas que se inserem nas relações sociais e que cumprem um importante papel em todas as esferas do desenvolvimento (biológico, cognitivo, afetivo, etc.) e que têm início desde os primeiros momentos de vida, a partir das relações e interações mediadas pelos processos de comunicação e metacomunicação estabelecidos entre os seres humanos e que perduram por toda a vida.

Dessa maneira, partindo de um enfoque sistêmico e interdisciplinar do desenvolvimento humano, observa-se uma intrínseca relação entre desenvolvimento e aprendizagem enquanto aspectos coconstruídos nos processos de socialização que acontecem durante a vida. Em outras palavras, a partir de uma perspectiva dialógica, a relação entre as práticas sociais, a emergência dos processos comunicativos e o processo de desenvolvimento e aprendizagem não pode ser observada isoladamente, uma vez que esses três elementos se manifestam, mas de forma interdependente. Sendo, pois, o desenvolvimento humano caracterizado pelas mudanças e reorganização contínua do indivíduo durante o curso de vida, este desenvolvimento dependerá das interações sociais constituídas, apesar de não ser determinada apenas por elas (VALSINER, 1989).

Reconhecemos, portanto, o contexto da escola como ambiente privilegiado para impulsionar o desenvolvimento da linguagem, o que por sua vez influenciará o desenvolvimento global. Acreditamos que esses suportes ao desenvolvimento da criança são estabelecidos pelas interações estabelecidas entre professor-aluno e entre aluno-aluno no contexto da escola e envolvem negociações, conflitos sociocognitivos, argumentações, questionamentos, discussões, aspectos metacomunicativos, que serão aspectos importantes na constituição subjetiva do sujeito e abrangem todas as práticas escolarizadas, desde os sistemas da escola regular, até os atendimentos tutoriais especializados e aqueles que compreendem a inclusão escolar.

\section{Inclusão escolar: problemas e perspectivas}

Discussões relativas ao desenvolvimento e aprendizagem estão ligadas à ideia de uma escola universal que atenda a todos. Essas questões 
refletem a busca e valorização da diversidade e respeito às diferenças, que também se traduzem pelo conceito de inclusão. O conceito de inclusão que conhecemos na atualidade é o reflexo histórico de uma série de discussões que vêm sendo construídas há muitos anos e têm suas bases nos movimentos sociais em prol da democratização do ensino.

Dados do Ministério da Educação apontam que entre 1998 e 2006 houve crescimento de $640 \%$ das matrículas de crianças com necessidades especiais em escolas comuns e de $28 \%$ em escolas e classes especiais. No entanto, verifica-se que, apesar do crescimento de matrícula de crianças com necessidades especiais em classes regulares, em diversos casos essas crianças não obtêm grandes avanços no processo de inclusão escolar no que se refere à aprendizagem. Em muitas classes inclusivas, as interações estabelecidas pelas crianças com deficiência são mais restritas se comparadas com as interações que ocorrem entre as crianças sem deficiência (BATISTA; ENUMO, 2004; LACERDA, 2006), fato que se acentua quando a necessidade especial afeta a comunicação oral (PAULA; ENUMO, 2007; PRÉNERON, 2006; TETZCHNER et al., 2005).

A educação formal é um dos aspectos fundamentais para a coconstrução dos seres humanos, portanto, é um direito de todos. Esse direito não se fundamenta apenas no acesso à educação, mas sobretudo na garantia de permanência dos educandos na escola. Embora a legislação e outros documentos reafirmem o direito a uma educação de qualidade preferencialmente no sistema regular e apesar dos novos entendimentos no que se refere à educação de pessoas com deficiência, ainda identificamos práticas denominadas inclusivas que não conseguem atingir seus objetivos de promoção da aprendizagem. O processo inclusivo necessita melhorar as práticas em vários aspectos e vencer a segregação que em muitos casos se instala dentro da sala de aula. Para Von Tetzchener et al. (2005, p. 154), "muitas vezes as crianças com deficiência são meras observadoras das atividades que outras crianças de sua unidade ou classe estão realizando na préescola, mesmo quando estão matriculadas em pré-escolas não segregadas".

Conforme se observa, o número de matrículas de crianças com deficiência em classes regulares tem aumentado significativamente nos 
últimos anos, porém pesquisas têm indicado que ainda é um desafio grande atingir níveis de aprendizagem satisfatórios. Estudos como os de Carvalho (2007), Kelman (2005), Lacerda (2006), por exemplo, mostram que embora o processo de inclusão seja um avanço no que concerne à educação de pessoas com necessidades especiais, especialmente por se caracterizar como um modelo que se contrapõe aos modelos segregadores, esse processo nem sempre oferece ou garante os melhores recursos educativos nem as relações de interação mais proveitosas para a construção do conhecimento da pessoa com necessidade especial. $O$ fato revela que o movimento pela inclusão de pessoas com necessidades especiais, precisa avançar em termos de práticas mais eficazes de ensino-aprendizagem.

Por outro lado, apesar de ainda serem detectados muitos problemas a partir da prática de inclusão escolar, ainda assim consideramos o modelo de educação inclusiva benéfica para a educação de todos os que dela participam. Pesquisas indicam que, de forma geral, as crianças incluídas aprendem e se desenvolvem melhor do que se estivessem em escolas segregadas. Além disso, mesmo as crianças não deficientes se beneficiam desse modelo, uma vez que os princípios que baseiam as práticas inclusivas são incentivados e cultivados em todo o grupo, princípios estes que envolvem construção de conceitos e valores importantes como atitudes de solidariedade, cooperação, valorização da diversidade, entre outros. Estudos mostram que as expectativas e relações sociais diante da deficiência mudam a partir do convívio com pessoas que possuam necessidades especiais (OMOTE et al., 2005). Essas conclusões ratificam a opção por sistemas inclusivos, mas ainda é necessário que estudos empíricos venham contribuir para melhor entendimento dessas práticas, refletindo, desse modo, para a melhoria do processo de ensino-aprendizagem.

\section{Descrição do estudo empírico}

Realizou-se um estudo com o intuito de identificar e analisar processos de desenvolvimento da linguagem oral e suas implicações para 
a aprendizagem, a partir das relações sociais, com foco específico nas interações entre pares. $\mathrm{O}$ interesse foi de contribuir para a compreensão de aspectos relativos às interações criança-criança no espaço escolar e à influência dessas interações no desenvolvimento daquelas que apresentavam atrasos no desenvolvimento da linguagem. Nesse sentido, observamos a frequência com que ocorriam as interações criança-criança, a qualidade dessas interações, as estratégias de comunicação adotadas e os momentos significativos de coconstrução da linguagem.

Os dados aqui apresentados fazem parte desse estudo mais amplo desenvolvido a partir de um estudo de caso. Foram realizadas observações da rotina escolar registradas em notas de campo, entrevistas semiestruturadas e gravação em vídeo de episódios de interação. Os dados foram analisados e discutidos com base em uma abordagem interpretativa, baseada na perspectiva sociocultural-construtivista. Dos episódios registrados em vídeo, alguns foram selecionados para análise a partir de uma orientação microgenética (BRANCO; ROCHA, 1998; BRANCO; VALSINER, 1999; GÓES, 2000; ROSSETI-FERREIRA; AMORIM; SILVA, 2004).

Sobre a análise microgenética, Góes (2000, p. 25) afirma:

a caracterização mais interessante da análise microgenética está numa forma de conhecer que é orientada para minúcias, detalhes e ocorrências residuais, como indícios, pistas, signos de aspectos relevantes de um processo em curso; que elege episódios típicos ou atípicos (não apenas situações prototípicas) que permitem interpretar o fenômeno de interesse; que é centrada na intersubjetividade e no funcionamento enunciativo-discursivo dos sujeitos; e que se guia por uma visão indicial e interpretativo-conjetural.

Dessa maneira, o estudo descreveu e analisou situações de interação criança-criança em uma turma do $3^{\circ}$ período de uma escola de educação infantil, da rede pública de Brasília, DF. Foram participantes principais do estudo duas crianças gêmeas univitelinas com 5 anos de idade que possuíam atrasos significativos no processo de aquisição linguística, aqui identificados como Tadeu e Marcelo (nomes fictícios). 
As análises foram desenvolvidas com base na observação das interações estabelecidas e nas estratégias de comunicação (verbal e não verbal), bem como nas possibilidades de coconstrução do desenvolvimento e aprendizagem, notadamente da linguagem oral, que emergiram dessas interações. Em outras palavras, nas análises procurou-se perceber o que as interações nos revelam acerca do processo de inclusão e, em especial, a partir das estratégias comunicativas utilizadas durante as interações criança-criança.

Considerando as proposições de Pedrosa e Carvalho (2005) acerca da análise de episódios interativos, selecionou-se um trecho de episódio com duração de 2 minutos e 46 segundos ocorrido na brinquedoteca da escola. De acordo com as autoras, "um episódio é uma sequência interativa clara e conspícua, ou trechos do registro em que se pode circunscrever um grupo de crianças a partir do arranjo que formam e/ ou da atividade que realizam em conjunto". Reforçando a importância da análise de episódios ou sequências interativas em estudos qualitativos, Carvalho et al. (2002, p. 93) afirmam:

a análise de sequências talvez seja o procedimento mais conhecido e elaborado de análise de dados observacionais com o objetivo de descrever o fluxo dos eventos ou suas relações temporais. Desse modo, com base nessas discussões, a pesquisa mais ampla utilizou como base de dados, entre outros, episódios e sequências interativas gravadas em vídeo.

Sendo assim, como forma de ilustrar o trabalho de análise realizado durante o estudo, selecionou-se um curto episódio interativo gravado em vídeo que será apresentado a seguir. É importante ressaltar, contudo, que o episódio selecionado trata-se de apenas um recorte entre vários episódios que compõem o corpus de dados da pesquisa, sendo utilizado com caráter ilustrativo neste artigo. A escolha de tal episódio para apresentação justifica-se pela síntese representativa acerca dos dados coletados durante o desenvolvimento do estudo. 


\section{O episódio interativo}

Foi levado para a brinquedoteca da escola um grupo de dez crianças, com idades variando entre 4 e 5 anos. No episódio transcrito estão em evidência os gêmeos Marcelo e Tadeu e três colegas aqui batizados de Rodrigo, Isabel e Maria. O foco do episódio selecionado está na relação estabelecida entre os gêmeos e alguns colegas, motivada pela brincadeira com balões de ar que estavam dispostos pela sala e outros objetos utilizados como mediadores de interação.

Quadro 1 - Episódio “Quer balão?”

(Continua)

\begin{tabular}{|c|c|}
\hline Curso & $\begin{array}{l}\text { Crianças em interação } \\
\text { Descrição das ações e falas }\end{array}$ \\
\hline $0^{\prime} 00^{\prime} 05$ & $\begin{array}{l}\text { As crianças se espalham pela sala selecionando brinquedos diversos. Um grupo } \\
\text { escolhe brincar com balões de ar que estavam disponíveis na sala e passam a jogá-los } \\
\text { para o alto. Nesse grupo estão os gêmeos Tadeu e Marcelo. As crianças gritam e riem, } \\
\text { demonstrando satisfação com a brincadeira. Rodrigo, enquanto joga os balões, grita: } \\
\text { "baão, baão...". Marcelo observa sorrindo. Em determinado ponto da brincadeira, } \\
\text { Tadeu aponta para balões localizados no alto da estante tentando chamar a atenção } \\
\text { de um colega e diz: "O... baão...". }\end{array}$ \\
\hline $0^{\prime} 01^{\prime} 03$ & $\begin{array}{l}\text { Rodrigo indica que irá abandonar a brincadeira com os balões: "Não quero mais } \\
\text { brincar disso", e vai ao encontro de outro grupo de crianças. Os gêmeos permanecem } \\
\text { brincando com os balões. }\end{array}$ \\
\hline $0^{\prime} 01^{\prime} 08$ & $\begin{array}{l}\text { Os gêmeos percebem balões em outro espaço da sala e seguem para buscá-los. } \\
\text { Um deles procura trazer Rodrigo novamente para a brincadeira, tentando chamar } \\
\text { sua atenção. Para isso, recorre a uma estratégia não verbal (apontando e tocando } \\
\text { insistentemente no colega, que está entretido com objetos), sem sucesso. Diante da } \\
\text { ineficácia da estratégia, procura comunicar-se a partir da linguagem verbal: "eeei, eei...". }\end{array}$ \\
\hline $0^{\prime} 01^{\prime} 39$ & $\begin{array}{l}\text { Ao fundo da sala um grupo de crianças brinca com o túnel de tecido. Marcelo pega } \\
\text { um dos balões e se aproxima desse grupo. Observa e em seguida tenta jogar um balão } \\
\text { dentro do túnel, sendo repreendido por Maria: "Ei, para! Não é pra jogar balão aí!". } \\
\text { Marcelo se retira. }\end{array}$ \\
\hline $\begin{array}{l}0^{\prime} 01^{\prime} 37 \\
\text { até } \\
0^{\prime} 02^{\prime} 35\end{array}$ & $\begin{array}{l}\text { Os gêmeos passeiam pela sala observando os colegas brincarem. Observam atentamente } \\
\text { as brincadeiras e interações. Tentam aproximar-se de alguns grupos, mas sem inves- } \\
\text { timento direto. Permanecem mais tempo observando os colegas do que brincando. }\end{array}$ \\
\hline
\end{tabular}

Rev. Diálogo Educ., Curitiba, v. 11, n. 32, p. 225-245, jan./abr. 2011 
Quadro 1 - Episódio "Quer balão?”

(Conclusão)

\begin{tabular}{ll}
\hline Curso & \multicolumn{1}{c}{$\begin{array}{c}\text { Crianças em interação } \\
\text { Descrição das ações e falas }\end{array}$} \\
\hline $\begin{array}{l}\text { 0'02'34 } \\
\text { até } \\
0^{\prime} 02^{\prime} 38\end{array}$ & $\begin{array}{l}\text { Tadeu utiliza um bicho de pelúcia para estabelecer contato. Tadeu pega o bicho de } \\
\text { pelúcia com a mão, aproxima-se de Isabela e chacoalha o corpo e grita "oooohh", } \\
\text { aparentemente imitando o barulho de um animal. A colega responde com atitude de } \\
\text { espelhamento, imitando o mesmo gesto e som. }\end{array}$ \\
\hline 0'02'46 & $\begin{array}{l}\text { Isabela se afasta. Percebendo o afastamento, Tadeu tenta a reaproximação e diz, } \\
\text { apontando para o alto: "Qué baão?". }\end{array}$ \\
\hline
\end{tabular}

Fonte: Dados da pesquisa.

\section{Análise e discussão}

Com base no episódio verifica-se que, ao chegar à brinquedoteca, as crianças se dividiram pela sala. Rapidamente grupos se formaram em torno de interesses e selecionaram objetos e brinquedos que mais chamaram a atenção, havendo negociação em torno das brincadeiras e dos objetos selecionados. Observa-se que os gêmeos adotam diversas estratégias para chamar a atenção dos colegas, procurando desse modo estabelecer interação. As ações são variadas e se apoiam em estratégias comunicativas verbais e não verbais, embora privilegiem o contato a partir de aspectos não verbais, muitas vezes mediados pelo uso de objetos. Observa-se o uso recorrente de palavras autônomas (sem significado na língua corrente). Em alguns momentos verifica-se que a estratégia é bem-sucedida, como no caso do bicho de pelúcia, em que a reciprocidade da colega imitando o mesmo som nos leva a supor que a relação proposta foi bem aceita. Em outros, ao contrário, as estratégias não foram bem-sucedidas, já que não cumpriram a intenção de inseri-los como participantes da brincadeira, resultando em rejeição, como no caso do balão atirado ao túnel, por exemplo (turno 1'39).

Desse modo, as interações mediadas por meio de objetos revelaram-se como estratégia importante na tentativa de estabelecer contato. 
Verifica-se que tanto o bicho de pelúcia quanto os balões foram usados como instrumentos mediadores para estabelecer um contato inicial ou para manter interações já estabelecidas (conforme turnos 0'05; 1'08; 1'39; 2'38). Observa-se que os gêmeos, na maior parte do tempo, optaram por utilizar de estratégias não verbais para estabelecer relações; contudo, em algumas situações, dada a pouca eficiência dessas estratégias, optaram pelo uso da linguagem verbal, o que revela um espaço e possibilidades significativas para a construção do conhecimento, a partir das trocas interativas.

Com relação ao tipo de linguagem utilizada pelos gêmeos, verificou-se tanto o uso de palavras autônomas, isto é, palavras sem significado na língua corrente, quanto o de palavras correntes da língua (LURIA; YUDOVICH, 1985). O uso da linguagem oral ocorreu especialmente como forma de manter interações já estabelecidas, principalmente quando estratégias não verbais falharam. Apesar de se observar na comunicação oral dos gêmeos o uso de palavras presentes na língua corrente, não se observou linguagem narrativa. A linguagem apresentou-se, na maior parte das vezes, constituída por frases curtas, ligadas à experiência imediata e situações concretas. Sendo uma forma de linguagem menos elaborada, está relacionada a pedidos, opiniões, indicações ou afirmativas simples, o que Luria e Yudovich (1985) denominam linguagem simpráxica. Verifica-se, assim, tentativas sucessivas de se estabelecer e manter interações, o que primeiramente ocorre de forma gestual e vai gradualmente progredindo para o uso da linguagem verbalizada.

Verificou-se que o contato, a comunicação e interação com os colegas eram valorizadas e buscadas por eles. A linguagem utilizada pelos gêmeos, por apresentar uma configuração peculiar, acabava por dificultar o entendimento por parte dos interlocutores, o que muitas vezes prejudicava o processo interativo. No entanto, podemos afirmar, a partir dos dados analisados, que a linguagem verbal apresentada pelos gêmeos era utilizada de forma intencional, visando a atingir o "Outro" durante os processos interativos. Observaram-se tentativas de se contornar as dificuldades apresentadas na utilização da linguagem, conforme observado nas 
estratégias de uso de objetos mediadores. Isso indica que as oportunidades de interação entre pares configuram-se como espaço para a coconstrução da linguagem, na medida em que demanda a utilização dela, quando as outras formas de comunicação não se mostram tão eficientes (turnos 1'08; 2'46). Isso denota o jogo de negociação para aproximação e continuidade da brincadeira, de forma que o uso da linguagem oral indica claramente a intenção de estabelecer interações.

A imitação ou atitude de espelhamento verificada na comunicação das crianças revelou-se como uma ação importante na interação comunicativa delas. Esse fato nos leva a crer que esse tipo de interação estabelecida se aproxima do conceito de Zona de Desenvolvimento Proximal (ZDP). De acordo com Luria e Yudovich (1985, p. 69),

a criança, quando entra numa situação complexa, pode imitar ações que ainda não consegue fazer sozinha. E esta participação em formas mais complexas de atividade é o que justamente vai habilitá-la para chegar ao nível de aquisição destas ações de maneira independente.

Portanto, podemos afirmar que as atitudes de espelhamento, tão comuns nas observações, constituíam-se como uma atuação constante atuação na ZDP dessas crianças e, portanto, no desenvolvimento e na construção do conhecimento. Embora se identifique claramente o déficit no desenvolvimento da oralidade, é possível supor que as possibilidades e o interesse em estabelecer relações acabam por motivar a utilização da linguagem verbal. Isso pode ser compreendido como uma forma de atuação na Zona de Desenvolvimento Proximal, no que se refere ao uso da linguagem verbal, o que se configura como uma possibilidade de desenvolvimento e aprendizagem.

Compreende-se, portanto, que tais situações que acabam por exigir o uso da linguagem se constituem como meios fecundos para o desenvolvimento dessas crianças. As interações estabelecidas, bem como as diferentes estratégias comunicativas utilizadas, acabam por propiciar a coconstrução da aprendizagem a partir das relações estabelecidas na 
escola. Em outras palavras, podemos afirmar que as situações interativas que acontecem acabam, em alguns momentos, por criar situações que exigiam o uso da linguagem verbal e, consequentemente, possibilidades de avanços significativos no desenvolvimento não só desta habilidade, mas acerca da aprendizagem de forma global.

\section{Conclusões}

As estratégias comunicativas muitas vezes são mediadas por outros instrumentos que não a palavra. As interações estabelecidas neste episódio acontecem a partir de diferentes formas e estratégias. Os resultados, ilustrados neste artigo com base no curto episódio analisado, indicam que a linguagem verbal foi utilizada principalmente para iniciar ou manter interações com seus pares, o que ressalta a característica social do uso da linguagem. As interações estabelecidas foram especialmente do tipo díade (criança-criança) ou em pequenos grupos.

Observou-se que em algumas situações os gêmeos utilizaram a linguagem oral, quando outras formas de comunicação não foram suficientes. Embora tenhamos observado os gêmeos em interação com outras crianças utilizando a linguagem oral (mesmo que na maior parte das vezes de forma inteligível), não se observou intervenção dos gêmeos em processos de negociação que necessitavam de discursos orais mais elaborados. O estudo indicou que o espaço de interação propiciado nessa instituição era extremamente favorável à aprendizagem e desenvolvimento dos gêmeos. Contudo, sob nosso ponto de vista, o espaço poderia ser mais bem explorado, especialmente quando no que se refere às possibilidades de promoção e desenvolvimento da linguagem, dada a especificidade do trabalho pedagógico que a educação infantil pode proporcionar.

Esta pesquisa, realizada em uma instituição que atua com educação infantil e que trabalha com crianças em processo de inclusão, permitiu que, por meio da construção dos dados feita a partir das observações realizadas em diferentes espaços da escola, a partir da análise 
microgenética dos episódios de interação e a partir de outros recursos metodológicos adotados, fossem revelados alguns aspectos que, de certa maneira, esperávamos encontrar, assim como possibilitou outras descobertas. Embora esperássemos que as interações estabelecidas fossem ser mais restritas, em virtude das peculiaridades no desenvolvimento da linguagem verbal, apresentadas pelos sujeitos deste estudo, a realidade observada é que as crianças estavam em constante processo interativo e de coconstrução. Inferimos daí a importância do contexto inclusivo como forma e meios de atuação para a construção significativa de avanços no desenvolvimento. Contudo, é possível supor que o déficit de linguagem influencia de certa maneira a qualidade dos processos interativos estabelecidos.

Os estudos teóricos realizados combinados aos resultados do estudo empírico realizado nos levam a crer que, embora no plano das ideias o conceito de inclusão esteja bastante avançado, este é, no campo prático, bastante deficitário. Isso significa que a matrícula de crianças com necessidades especiais em classes regulares, não garante por si só a inclusão de fato. É sabido que, para que a inclusão em classes regulares ocorra com sucesso, a escola e seus atores precisam combinar esforços buscando as mais diversas adaptações, sejam elas físicas, curriculares, metodológicas, ou outras necessárias com vistas a atender esses alunos.

Ampliando as percepções do estudo realizado, verificamos que salientar a importância do "outro social" no processo de desenvolvimento vem ao encontro de movimentos em prol dos modelos de educação inclusivos. Dessa forma, o processo de inclusão escolar deve refletir um modelo educativo que aumente as possibilidades de se estabelecer laços e atitudes positivas diante das pessoas com necessidades especiais, uma vez que o contexto inclusivo pode configurar-se como um espaço rico em situações interacionais e, portanto, propício ao desenvolvimento e à aprendizagem.

Uma das grandes dificuldades da inclusão ainda é propiciar momentos e atividades em sala de aula que considerem todos os alunos envolvidos, independente de suas características. Por isso, faz-se 
necessário que discussões que há muito têm dominado o discurso acadêmico encontrem ecos na prática pedagógica e reflitam-se em ações educativas que contemplem as diferenças presentes em qualquer sala de aula. O sucesso processo inclusivo se apresenta atualmente como objeto de diversas áreas do conhecimento e pressupõe um caminho cheio de imprevistos que exige avaliação constante e, por constituir um tema tão complexo, implica modificações profundas das práticas escolares, o que impõe a necessidade de se intensificarem as pesquisas e estudos empíricos nesta área.

\section{Referências}

ANJOS, A. M. dos et al. Interações de bebês em creche. Estudos de Psicologia, Natal, v. 9, n. 3, p. 513-522, 2004.

BATISTA, M. W.; ENUMO, S. R. F. Inclusão escolar e deficiência mental: análise da interação social entre companheiros. Estudos de Psicologia, Vitória, v. 9, n. 1, p. 101-111, 2004.

BRANCO, A. U. Crenças e práticas culturais: coconstrução e ontogênese de valores sociais. Pro-Posições, Campinas, v. 2, n. 50, p. 139-155, 2006.

BRANCO, A. U.; ROCHA, R. F. A questão da metodologia na investigação científica do desenvolvimento humano. Psicologia: Teoria e Pesquisa, Brasília, v. 14, n. 3, p. 251-258, 1998.

BRANCO, A. U.; VALSINER, J. A questão do método na psicologia do desenvolvimento: uma perspectiva coconstrutivista. In: PAZ, M. das G. T.; TAMAYO, A. (Org.). Escola, saúde e trabalho: estudos psicológicos. Brasília: Ed. UnB, 1999. p. 23-29.

BORGES, L. C.; SALOMÃO, N. M. R. Aquisição da linguagem: considerações da perspectiva da interação social. Psicologia: Reflexão e Crítica, Porto Alegre, v. 16, n. 2, p. 327-336, 2003. 
CARVALHO, E. N. S. de. Interação entre pares na educação infantil: exclusão-inclusão de crianças com deficiência intelectual. 2007. Tese (Doutorado em Psicologia) - Instituto de Psicologia, Universidade de Brasília, Brasília, 2007.

CARVAlHO, A. M. A. et al. Dinâmica interacional de crianças em grupo: um ensaio de categorização. Psicologia em Estudo, Maringá, v. 7, n. 2, p. 91-99, 2002.

GEERTZ, C. A transição para a humanidade. In: TAX, S. (Org.). Panorama da Antropologia. Rio de Janeiro; São Paulo; Lisboa: Fundo de Cultura, 1996. p. 31-43.

GOÉS, M. C. R. de. A abordagem microgenética na matriz histórico-cultural: uma perspectiva para o estudo da constituição da subjetividade. Cadernos Cedes, São Paulo, v. 20, n. 50, p. 9-25, 2000.

KELMAN, C. A. “Aqui tudo é importante!” Interações de alunos surdos com professores e colegas em espaço escolar inclusivo. 2005. Tese (Doutorado em Psicologia) - Instituto de Psicologia, Universidade de Brasília, Brasília, 2005.

LACERDA, C. B. F. de. A inclusão escolar de alunos surdos: o que dizem os alunos, professores e intérpretes sobre esta experiência. Cadernos Cedes, São Paulo, v. 26, n. 69 , p. 163-184, 2006.

LURIA, A. R.; YUDOVICH, F. I. Linguagem e desenvolvimento intelectual da criança. Porto Alegre: Artes Médicas, 1985.

MACIEL, D. A. Análise da interação professora-criança em situação de ensino- aprendizagem da leitura e escrita. 1996. Tese (Doutorado em Educação) - Faculdade de Educação, Universidade de São Paulo, São Paulo, 1996.

MACIEL, D. A.; BRANCO, A. U.; VALSINER, J. Bidirectional process of knowledge construction in teacher-student transaction. In: BRANCO, A. U.; VALSINER, J. (Org.). Communication and metacommunication in a human development. Greenwich, CT: Information Age Publishing, 2004. p. 109-125. 
MADUREIRA, A. F.; BRANCO, A. U. Construindo com o outro: uma perspectiva sociocultural construtivista do desenvolvimento humano. In: DESSEN, M. A.; COSTA Jr., A. (Org.). A ciência do desenvolvimento humano: tendências atuais e perspectivas futuras. Porto Alegre: Artmed, 2005. p. 89-109.

OMOTE, S. et al. Mudança de atitudes sociais em relação à inclusão. Paideia: Cadernos de Psicologia e Educação, São Paulo, v. 15, n. 32, p. 387-396, 2005.

PAULA, K. M. P. de; ENUMO, S. R. F. Avaliação assistida e comunicação alternativa: procedimentos para a educação inclusiva. Revista Brasileira de Educação Especial, Marília, v. 13, n. 1, p. 3-26, 2007.

PEDROSA, M. I.; CARVALHO, A. M. A. Análise qualitativa de episódios de interação: uma reflexão sobre os procedimentos e formas de uso. Psicologia: Reflexão e Crítica, Porto Alegre, v. 18, n. 3, p. 431-442, 2005.

PRÉNERON, C. Distúrbios da linguagem oral e da comunicação na criança. In: DEL RÉ, A. (Org.). Aquisição da linguagem: uma abordagem psicolinguística. São Paulo: Contexto, 2006. p. 63-83.

ROGOFF, B. A natureza cultural do desenvolvimento. Porto Alegre: Artes Médicas, 2006.

ROSSETI-FERREIRA, M. C.; AMORIM, K. S.; SILVA, P. S. Rede de significações e o estudo do desenvolvimento humano. Porto Alegre: Artmed, 2004.

VALSINER, J. Human development and culture: the social nature of personality and its study. Lexington, MA: Lexington Books, 1989. p. 1-42.

VALSINER, J. The guided mind: a sociogenetic approach to personality. Cambridge, MA: Harvard University Press, 1998.

VALSINER, J. Approaches to culture: semiotic bases for cultural psychology. In: VALSINER, J. Culture in minds and societies: foundations of cultural psychology. New Delhi: Sage, 2007. p. 19.

VYGOTSKY, L. S. Pensamento e linguagem. São Paulo: Martins Fontes, 1993. 
VYGOTSKY, L. S. The problem of the environment. In: VAN DER DEER, R.; VALSINER, J. (Org.). The Vygotsky reader. Oxford, UK: Basil Blackwell, 1994. p. 338-354.

TETZCHNER, S. V. et al. Inclusão de crianças em educação pré-escolar regular utilizando comunicação suplementar e alternativa. Revista Brasileira de Educação Especial, Marília, v. 11, n. 1, p. 151-184, 2007.

Recebido: 22/03/2010

Received: 03/22/2010

Aprovado: 22/06/2010

Approved: 06/22/2010 